\title{
UTILIZAÇÃO DE UMA OFICINA COMO AUXÍLIO AO ENSINO NO CURSO DE NUTRIÇÃO
}

\section{WORKSHOP USE AS AID TO NUTRITION COURSE TEACHING}

\author{
Paula Alves Leoni ${ }^{1}$, Denise Celeste Godoy de Andrade Rogrigues ${ }^{2}$ \\ ${ }^{1}$ Centro Universitário de Volta Redonda - UniFOA/ Docente do Curso de Nutrição, \\ la_leoni@hotmail.com \\ ${ }^{2}$ Centro Universitário de Volta Redonda - UniFOA/ Docente do Programa de Mestrado Profissional em \\ Ensino em Ciências da Saúde e do Meio Ambiente, denise.cgar@gmail.com
}

\begin{abstract}
RESUMO
A demanda pela qualidade da formação profissional do nutricionista tem aumentado. Enfatiza-se a necessidade de mudança na prática pedagógica e a utilização de novas metodologias para que possam emergir melhores condições de aprendizagem para os alunos. Esse trabalho teve como objetivo propor uma nova forma de se trabalhar o conteúdo da disciplina Patologia da Nutrição e Dietoterapia, que faz parte da matriz curricular do curso de Nutrição do Centro Universitário de Volta Redonda . Trata-se de uma pesquisa descritiva com abordagem qualitativa, realizada em duas etapas: de diagnóstico e de avaliação da oficina. A coleta de dados ocorreu por meio da aplicação de questionários e as respostas foram analisadas por intermédio da tematização proposta por Fontoura. Dentre os resultados obtidos, encontram-se a insegurança dos alunos quanto à relação teoria e prática e a preocupação dos mesmos de não alcançarem o entendimento necessário acerca do conteúdo proposto. Sobre a importância de haver uma nova metodologia para ser utilizada junto à referida disciplina, $86 \%$ dos alunos do $5^{\circ}$ período e $80 \%$ do $6^{\circ}$ responderam de forma positiva à questão. Entre os materiais de apoio que poderiam facilitar a aprendizagem, $69 \%$ dos alunos optaram pela realização de uma oficina. A análise das respostas dos alunos, que participaram da oficina, acerca da proposta metodológica utilizada demonstra que os mesmos ficaram satisfeitos e avaliaram positivamente a utilização da oficina como ferramenta de apoio ao ensino dessa disciplina Concluiu-se que os alunos almejam aulas que se diferenciem do modelo tradicional e buscam novas formas de aprendizado.
\end{abstract}

Palavras-chave: nutrição; ensino superior; oficinas de aprendizagem.

\begin{abstract}
The demand regarding nutritionist professional qualification quality has increased. It is emphasized the need of changing in teaching practice and use of new methodologies in order that it can emerge better learning conditions for students. This work has as objective to propose a new way of working the discipline Nutrition Pathology and Diet Therapy content, which is part of the Nutrition Course curriculum of the Volta Redonda's University Center. It is a descriptive research with qualitative approach, realized in two steps: workshop diagnosis and evaluation. The data collect occurred by means of questionnaires application and the answers were analyzed through theming proposed by Fontoura. Among the results obtained lies the students insecurity towards the relationship between theory and practice and their concern in don't achieve the necessary understanding about the proposed content. About the importance of having a new methodology to be used at the said discipline, $86 \%$ of the $5^{\text {th }}$ grade students and $80 \%$ of the $6^{\text {th }}$ grade answered positively to the question. Among the support materials that could facilitate learning, $69 \%$ of the students choose a workshop performing. The students, that participated in the workshop, answers analysis about the use of the
\end{abstract}


methodological proposal shows that they were satisfied and evaluated positively the use of the workshop as learning support tool of this discipline. The conclusion is that students aim classes that differentiated from traditional model and search for a new way of learning.

Key words: nutrition; higher education; learning workshops.

\section{INTRODUÇÃO}

No Brasil, os primeiros cursos de Nutrição datam do final da década de 30 e início da década de 40 do século passado. Entretanto, somente na década de 60 os cursos de Nutrição foram reconhecidos como de nível superior, por meio do parecer $\mathrm{n}^{\circ}$ 265 de 19 de Outubro de 1962, emitido pelo Conselho Federal de Educação; e a profissão de Nutricionista foi regulamentada por meio da sanção da Lei no 5.276 de 24 de Abril de 1967. A partir desta data, observou-se um aumento no número de cursos de Nutrição no país, tendo esse se tornado mais expressivo a partir da instituição da Lei de Diretrizes e Bases da Educação em 1996, principalmente no setor privado, sendo ainda incipiente na saúde pública (VASCONCELOS e CALADO, 2011).

Os princípios, objetivos e metas das Diretrizes Curriculares dos cursos de nutrição, são comuns aos dos demais cursos da área da saúde e o documento se fundamenta nas diretrizes do Sistema Único de Saúde. De maneira geral, as habilidades e competências gerais do nutricionista estão relacionadas à saúde do indivíduo e da coletividade, à tomada de decisões baseadas em evidências científicas e às características necessárias para liderar, gerenciar e administrar. No que se refere às habilidades e competências específicas desse profissional tem-se a ênfase na atenção dietética, a qual engloba a manutenção e recuperação do estado nutricional dos indivíduos e da coletividade, ensino, atuação em políticas públicas ligadas à alimentação, administração na área de alimentação coletiva, auditoria, consultoria e marketing na área de alimentação, pesquisa e principalmente a visão holística do indivíduo (MOTTA, OLIVEIRA e BOOG, 2003).

Sendo assim, para que essa formação ocorra de forma expressiva, a estrutura do curso deve focar em um ensino crítico e reflexivo, que articule ensino, pesquisa e extensão/assistência; assegure a interdisciplinaridade e a educação para a cidadania; implemente metodologias que estimulem o aluno a "aprender a aprender", que articulem o saber, o "saber fazer" e o "saber conviver" com vistas a desenvolver no aluno o "aprender a ser", o "aprender a fazer", o "aprender a viver juntos" e o "aprender a 


\section{Ensino, Saúde e Ambiente - V9 (3), pp. 1-20, Dez. 2016}

conhecer". Nesse sentido, o curso de Nutrição deve ter um projeto pedagógico centrado no aluno como sujeito do processo ensino-aprendizagem e tendo o professor como facilitador desse processo (BRASIL, 2001; DELORS, 2010).

Nesse processo, o papel do professor seria o de proporcionar aos alunos situações desafiadoras para a construção do conhecimento, permitindo assim que os alunos discutam, negociem significados entre si, aprendam a fazer e receber críticas, tornando-os sujeitos ativos do processo e permitindo a aprendizagem de maneira significativa (PONTES, REGO e JÚNIOR, 2006).

Aprendizagem significativa é aprendizagem com significado. Isso acontece quando novos conhecimentos - conceitos, ideias, proposições, modelos, fórmulas passam a significar algo para o aprendiz, quando é capaz de explicar situações com suas próprias palavras e resolver problemas novos, ou seja, quando compreende (MOREIRA, 2003).

Essa aprendizagem se caracteriza pela interação entre os novos conhecimentos e aqueles já existentes na estrutura cognitiva do sujeito que aprende. Para que ocorra é necessária predisposição para aprender, o esforço deliberado, cognitivo e afetivo para relacionar de maneira não arbitrária e não literal os novos conhecimentos à estrutura cognitiva (MOREIRA, 2003).

Muito embora esse conceito de aprendizagem seja considerado o adequado, Debald (2003, p.2) ressalta que o grande desafio do professor em uma sala de aula no ensino superior consiste em encontrar uma forma adequada de transmitir o conteúdo para que haja adesão dos alunos no processo de discussão do tema proposto, visto que, muitas vezes, a dificuldade dos alunos encontra-se no processo metodológico e não no conteúdo, sendo assim, a passagem para um modelo de ensino baseado na construção do conhecimento significa para o professor enfrentar novos desafios bem como rever sua prática pedagógica.

Segundo Pedroso e Cunha (2008, p.143) “práticas pedagógicas de caráter inovador são aquelas que favorecem a ruptura com as formas tradicionais de ensinar e aprender", nessa perspectiva, ressalta-se a importância das oficinas pedagógicas.

Segundo Paviani e Fontana (2009, p.2) "a metodologia da oficina muda o foco tradicional da aprendizagem (cognição), passando a incorporar ação e reflexão". Ainda segunda as autoras, a finalidade de uma oficina consiste, sobretudo, em articular os conceitos com ações concretas vivenciadas pelos alunos, bem como a construção de um saber coletivo, visto que a mesma consiste em um trabalho em grupo, e dessa forma 
afirmam que "a construção dos saberes decorrem, principalmente, do conhecimento prévio, das habilidades, dos interesses, das necessidades, dos valores e julgamentos dos participantes" (PAVIANI e FONTANA, 2009, p.3).

De acordo com Moita e Andrade (2006, p.14), as oficinas tornam-se importantes dispositivos pedagógicos uma vez que dinamizam o processo de ensinoaprendizagem, estimulam a participação e criatividade dos seus participantes e ainda afirmam que:

\begin{abstract}
Com as oficinas, além de interagir, os (as) profissionais tanto ensinam quanto aprendem: ensinam, certamente, conteúdos formais de cuja transmissão são encarregados; aprendem, porque, como se sabe, essa transmissão não é automática, mas supõe uma construção cognitiva individual de cada aluno e aluna, favorecida pelo trabalho coletivo. Aprendem, por conseguinte, como pensam seus alunos - conhecimento esse indispensável para que possam cumprir uma tarefa complexa, a de facilitar a aproximação entre os saberes prévios do alunado e o saber sistematizado da escola (MOITA e ANDRADE, 2006, p.14).
\end{abstract}

Dessa forma entendemos as oficinas como uma excelente estratégia de ensino, visto que elas possibilitam em sua concepção a utilização de diversas metodologias em seu contexto, incluindo as metodologias ativas, que de acordo com Berbel (2011) tem potencial de despertar uma motivação autônoma nos alunos quando, através delas conseguir fortalecer a percepção do aluno de que ele é o sujeito de sua própria ação, ao serem apresentadas oportunidades de problematização de situações reais, bem como caminhos para o desenvolvimento de soluções, dentre outras possibilidades visto que as metodologias ativas tem potencial de despertar a curiosidade à medida que os alunos se inserem na teorização e trazem com eles novos elementos ainda não considerados nas aulas.

Entre as contribuições que podem ser atribuídas a essa proposta metodológica podemos destacar ao que se refere ao perfil dos profissionais almejados, principalmente aos da área de saúde, que de maneira geral precisam ter na sua formação características que incluem um profissional generalista, humanista, crítico, reflexivo e acima de tudo estar apto a resolução de problemas acerca da saúde tanto em nível individual quanto no coletivo, sendo estas características possíveis de se alcançar utilizando as metodologias ativas, visto que elas têm potencial de levar o aluno a se envolverem ativamente no seu processo de formação e consequentemente levando-os a uma aprendizagem para a autonomia (BERBEL, 2011).

Diante do exposto, o objetivo desse trabalho foi propor uma nova forma de se trabalhar o conteúdo da disciplina Patologia da Nutrição e Dietoterapia, esta que faz 
parte da matriz curricular do curso de Nutrição do Centro Universitário de Volta Redonda - UniFOA, e a partir da qual os alunos se instrumentalizam para realização do estágio obrigatório na área de Nutrição Social, o qual contempla o atendimento ambulatorial e também Nutrição Clínica que ocorre no âmbito hospitalar.

\section{METODOLOGIA}

Esse trabalho foi realizado como parte de uma pesquisa de dissertação de mestrado do Mestrado Profissional em Ensino em Ciências da Saúde e do Meio Ambiente do Centro Universitário de Volta Redonda - UniFOA.

O método utilizado nesse estudo foi de caráter descritivo, com abordagem qualitativa e a pesquisa constituiu-se de duas etapas distintas: na primeira etapa procurou-se levantar dados sobre as dificuldades dos alunos acerca do aprendizado da disciplina Patologia da Nutrição e Dietoterapia, bem como a opinião dos mesmos sobre que tipo de ferramenta de apoio ao ensino da referida disciplina atuaria como facilitador do processo ensino-aprendizagem; a segunda etapa consistiu na aplicação e avaliação da ferramenta proposta pela maioria dos alunos que participaram da primeira etapa.

Vale ressaltar que na matriz curricular do curso de Nutrição do UniFOA, a disciplina Patologia da Nutrição e Dietoterapia é a que possui uma maior carga horária, sendo esta constituída de 120 horas/aula no $5^{\circ}$ período e apresenta às seguintes competências: avaliação nutricional do indivíduo enfermo; prescrição de dietas e orientações ao indivíduo enfermo para promoção e recuperação da saúde; e 120 horas/aula no $6^{\circ}$ período com competências que vão desde as noções dos aspectos fisiopatológicos das enfermidades, até o conhecimento da importância do tratamento nutricional (UNIFOA, 2013).

Contudo, mesmo sendo uma disciplina de extrema importância, com um conteúdo bastante complexo, a mesma ainda é ministrada seguindo o modelo tradicional de ensino, ou seja, utilizando-se aulas expositivas e de transmissão do conhecimento baseada na "educação bancária”, forma de ensinar criticada por Paulo Freire (1987), onde o educador é o indivíduo que deposita seu conhecimento e os educandos são meros depositários.

A primeira etapa da pesquisa foi realizada em Maio de 2014, com 29 alunos do $5^{\circ}$ período e 15 alunos do $6^{\circ}$ período do Curso de nutrição do UniFOA. Para a realização da segunda etapa da pesquisa foram convidados todos os que participaram da primeira, 


\section{Ensino, Saúde e Ambiente - V9 (3), pp. 1-20, Dez. 2016}

entretanto contou somente com a participação de 5 alunos do $5^{\circ}$ período. Essa foi realizada no mês de Dezembro de 2014, no Centro Universitário de Volta Redonda UniFOA.

A coleta de dados das etapas da pesquisa se deu por meio de aplicação de um questionário em cada etapa, ambos contendo perguntas elaboradas de forma aberta e fechada.

As perguntas realizadas no questionário diagnóstico aplicado na primeira etapa da pesquisa indagavam sobre possíveis dificuldades que os alunos encontravam na aprendizagem da disciplina Patologia da Nutrição e Dietoterapia, sobre julgar a necessidade de haver uma nova metodologia para ser utilizada no ensino dessa disciplina e opções de ferramentas de apoio para facilitar o aprendizado do conteúdo da disciplina Patologia da Nutrição e Dietoterapia, com intuito de utilização das respostas como subsídio para propor uma nova maneira de trabalhar o conteúdo da referida disciplina.

A partir das respostas dos alunos foi elaborado um roteiro adaptado de Portela, Luke e Silva (2006) para realização de oficina pedagógica com intuito de nortear os professores que porventura vierem a utilizá-lo no que diz respeito ao processo de ensino-aprendizagem da disciplina Patologia da Nutrição e Dietoterapia, para que o mesmo possa vir a ser mais dinâmico e significativo.

As atividades desenvolvidas durante a oficina, bem como a ordem em que acontecerão e o tempo previsto de duração de cada atividade, constituem a parte mais importante do roteiro (Figura 1), visto que esse é que deverá ser seguido pelo profissional que estiver aplicando a oficina. O roteiro completo encontra-se disponível em http://web.unifoa.edu.br/portal ensino/mestrado/mecsma/arquivos/2015/paulaleoni-pd.pdf.

A oficina foi realizada com os 5 alunos do $5^{\circ}$ período que aceitaram participar da mesma. O tema da aplicação da oficina foi sugerido pela professora titular da disciplina, sobre o paciente hospitalizado, uma vez que os alunos haviam demonstrado uma maior dificuldade sobre esse assunto durante as aulas, e a oficina viria de encontro a essa dificuldade. Sobre o tema proposto inclui-se: avaliação nutricional (hábitos alimentares, antropometria, avaliação clínico nutricional), avaliação bioquímica, estimativa das necessidades nutricionais, recomendações do tratamento nutricional e forma de alimentação do paciente de acordo com a patologia apresentada (dieta normal, branda, pastosa, líquida, entre outras). 
A oficina proposta objetivava explicar os passos a serem seguidos até o momento de se colocar no prontuário do paciente todo tipo de conduta realizada pelo profissional nutricionista.

Não foi utilizado nenhum tipo de recurso tecnológico durante a realização da oficina, como por exemplo, data show. O material para consulta utilizado durante a oficina foi o conteúdo teórico dado em sala de aula pela professora da disciplina.

Vale ressaltar que essa oficina estava focada no uso da metodologia da problematização inserida no contexto de uma oficina pedagógica/aprendizagem. Sendo assim, o levantamento do conhecimento prévio dos alunos, a discussão em grupo, o uso de poucos materiais durante sua realização apresentou-se como uma forma adequada de conduzir a oficina.

Figura 1: Roteiro para realização de oficina

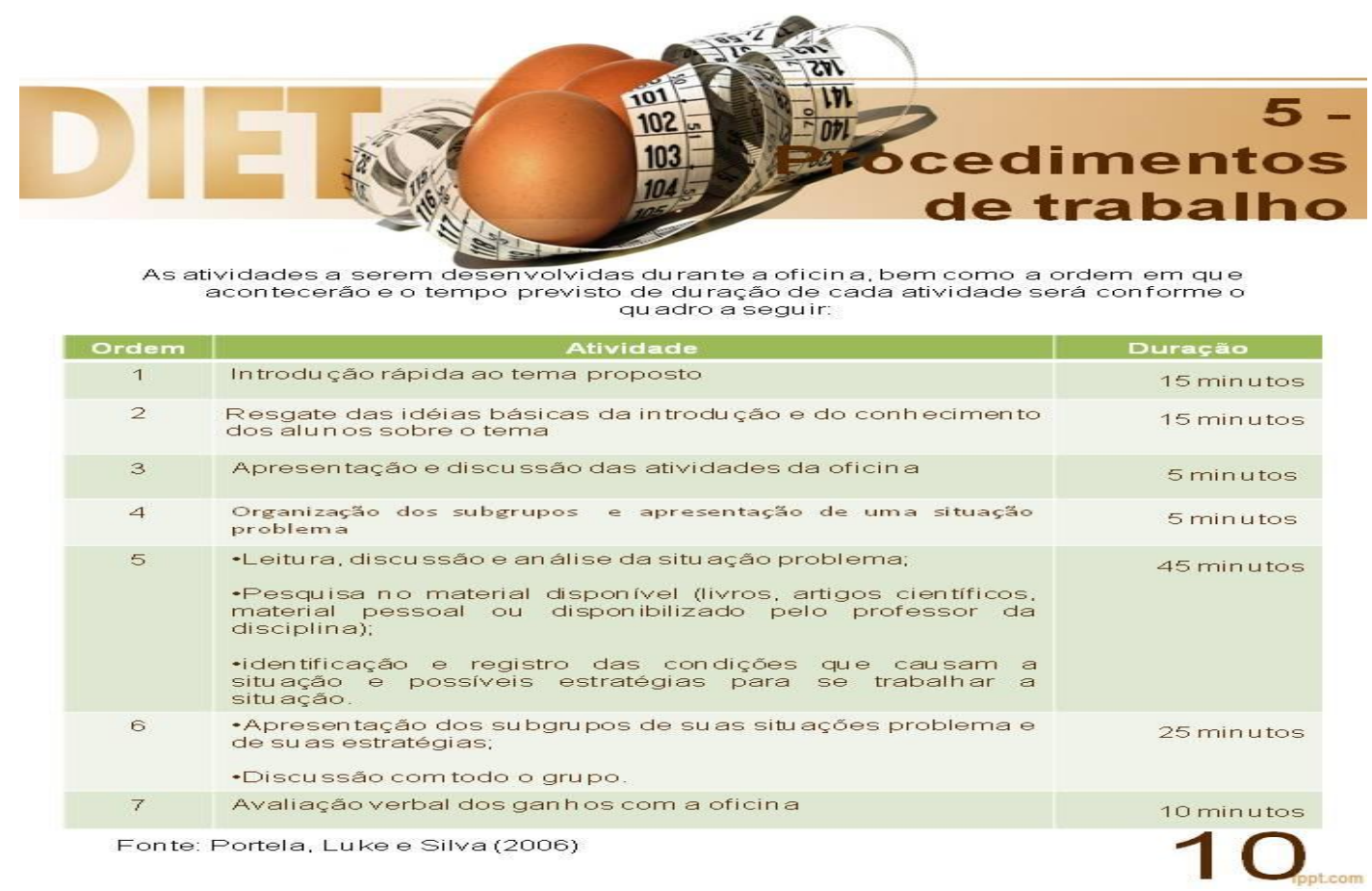

Fonte: Os autores

Na segunda etapa, no questionário de avaliação da oficina aplicado para avaliar a aceitabilidade e aplicabilidade da ferramenta proposta que constituiu da realização de uma oficina, as perguntas indagavam sobre a expectativa dos alunos com relação a oficina realizada, o tempo de duração, o uso da problematização como metodologia, os materiais e recursos utilizados, o conteúdo e, por fim a contribuição da utilização de oficinas como ferramenta de apoio ao ensino no desempenho acadêmico.

Os dados obtidos por meio das questões elaboradas de forma fechada foram 
analisados, e para melhor entendimento dos mesmos, foram explicitados de maneira quantitativa, como por exemplo, na forma de gráficos e tabelas.

No tratamento e a análise dos dados obtidos por meio da questão formulada de forma aberta e das respostas dos alunos utilizou-se a metodologia de tematização proposta por Fontoura (2011). e que utiliza as seguintes etapas:

$\checkmark \quad$ Transcrição do material coletado feita em perguntas abertas em questionário;

$\checkmark \quad$ Leitura do material;

$\checkmark \quad$ Demarcação do que foi considerado importante. Esses dados foram classificados de acordo com ideias-chave;

$\begin{array}{ll}\checkmark & \text { Levantamento dos temas de acordo com os dados agrupados; } \\ \checkmark & \text { Descobrir os núcleos de sentido que compõem a comunicação e cuja frequência }\end{array}$ de aparição pode ter significação para o objetivo analítico escolhido;

$\checkmark \quad$ Esclarecer o tratamento dos dados, a partir da separação das unidades do contexto do corpus, por meio da elaboração de tabelas, gráficos e organização de quadro das falas, onde é possível visualizar o panorama geral do encaminhamento da análise dos dados;

$\checkmark \quad$ Interpretação propriamente dita dos resultados à luz dos referenciais teóricos.

Para manter o anonimato dos alunos os dados obtidos no primeiro questionário, por meio da análise de conteúdo foram identificados pelas siglas A5 (aluno do $5^{\circ}$ período) e A6 (aluno do $6^{\circ}$ período). Os dados do segundo questionário foram identificados pela letra $\mathrm{P}$ e o número do participante (Ex. P1).

Os projetos foram submetidos e aprovados pelo Comitê de Ética em Pesquisas em Seres Humanos (CoEPS) do Centro Universitário de Volta Redonda - UniFOA, CAEE: 23311013.1.0000.5237 e CAEE: 36524214.7.0000.5237 e os alunos participantes assinaram o Termo de Consentimento Livre e Esclarecido, conforme Resolução nº196 de 10 de outubro de 1996, do Conselho Nacional de Saúde.

\section{RESULTADOS E DISCUSSÕES}

A partir da organização e da análise do conteúdo das respostas sobre o tema que norteou a primeira etapa da pesquisa "Levantamento das Dificuldades de Aprendizagem na disciplina Patologia da Nutrição e Dietoterapia", emergiram duas categorias assim denominadas: "Integração teoria e prática no ensino", que retrata a insegurança dos alunos quanto a essa relação; e "Aspectos didáticos”, que demonstra a 
preocupação dos mesmos de não alcançarem o entendimento necessário acerca do conteúdo proposto, o qual fará parte posteriormente da práxis profissional.

\section{INTEGRAÇÃO TEORIA E PRÁTICA NO ENSINO}

De acordo com Veiga (1991, p.136) a teoria deve ser um guia para a ação, sendo assim, a prática deve ser vista como a ação guiada e mediada pela teoria. Nesse sentido a importância de se integrar a teoria e a prática dentro do contexto de sala de aula se dá pelo fato de que os alunos tendem a se sentir inseguros ao colocarem em prática seus conhecimentos teóricos, adquiridos ao longo do curso, no momento em que se deparar com a realidade durante os estágios. As dificuldades apontadas acerca do tema são verificadas nas falas a seguir:

“Aplicação da matéria em situações práticas, visto que não existe fórmula absoluta para todos". (A5)

"Conciliar o que aprendemos nas aulas teóricas com a futura prática profissional". (A5)

"A falta de ensinamento na prática". (A5)

"Usar a teoria na prática, pois são muitos casos diferentes e as vezes paciente com mais de uma complicação". (A6)

"Ter só conteúdo teórico dentro da sala de aula, se o que a gente aprendesse dentro da sala fosse colocado em prática o aprendizado teria sido muito melhor". (A6)

Acreditamos que esse anseio dos alunos se justifica pelo fato de que, nesse momento em que eles se encontram já no terceiro ano da graduação, eles desejam se aproximar da realidade que os espera, enxergam a prática como uma ferramenta de assimilação eficaz a todo conteúdo estudado, e acima de tudo, se enxergarem verdadeiramente como futuros profissionais.

Franco e Boog (2007, p.654) ressaltam a importância da relação teóricoprática desde os primeiros anos da graduação, independente da disciplina, para que o aluno consiga estabelecer essa relação em suas ações ao longo de todo o curso, visto que a separação desses dois saberes constitui um fator complicador no desempenho profissional dos alunos quando estes não conseguem associar o contexto teórico no momento da prática.

A teoria nasce na prática que é sua fonte de desenvolvimento e forma de execução; isoladamente não gera transformações, não produz novas e inovadoras realidades, porque ela somente se concretiza por meio da prática, que a aperfeiçoa e a modifica, enquanto a teoria aprimora e transforma a própria prática. Assim, faz-se necessária a promoção de processo educacional crítico que, superando a mera 


\section{Ensino, Saúde e Ambiente - V9 (3), pp. 1-20, Dez. 2016}

transmissão de conhecimentos, permita a vivência plena da unicidade entre a teoria e a prática pedagógica (SOUZA, 2001).

\section{ASPECTOS DIDÁTICOS}

As dificuldades dos alunos apontadas, de uma maneira geral relacionam-se à forma como o conteúdo é apresentado, puramente teórica, sendo o mesmo muito extenso, conforme os relatos a seguir:

\footnotetext{
"Tem muita matéria para pouco tempo, com isso o professor passa muito depressa e não dá tempo de entender. Não tem muito exercício aplicado à disciplina". (A6) "Não consigo entender uma matéria, é muito complexa por isso acho que se utilizassem outros métodos para ensino tornaria mais interessante". (A6)

"Matéria bem extensa e complexa". (A6)

"A forma como as informações são passadas, é de maneira muito rápida e as explicações não são bem detalhadas. Além disso um material de estudo mais específico poderia ser disponibilizado". (A6)

"A matéria é junto com as patologias e por isso dificulta o aprendizado, a matéria é extensa e estudada muito rápido por isso não aprendemos com eficiência". (A5)

"Dificuldade em assimilar a matéria por ser um conteúdo muito extenso e com pouco tempo de aula". (A5)

"Associar as recomendações dietéticas com as diferentes patologias". (A5)

"A parte de exames bioquímicos, até porque não temos experiência na prática para melhorar e aprender na real". (A5)
}

Observa-se que até mesmo no discurso sobre o conteúdo, os alunos, apesar de muitas vezes inconscientemente, estão propondo uma ruptura ao modelo tradicional de ensino, pois por meio das falas sobre "muita matéria e pouco tempo", subentende-se que aulas de caráter puramente teórico não trazem significação e, consequentemente, não propiciam a aprendizagem de forma a preparar esse aluno a enfrentar os desafios no mercado de trabalho.

Trata-se do problema do conteúdo, que precisa ter coerência e ser ministrado de acordo com a vivência e realidade dos alunos. Neste aspecto didático, a abordagem dos conteúdos é vista como a ação recíproca entre a matéria, o ensino e o estudo dos alunos. Criam-se as condições para a assimilação consciente e sólida de conhecimentos, habilidades e atitudes, por meio do ensino. Isso possibilita aos alunos formar suas capacidades intelectuais para se tornar sujeitos da própria aprendizagem (RODRIGUES, MOURA e TESTA, 2011).

A aprendizagem significativa é oposta à aprendizagem mecânica na qual os conteúdos são meramente memorizados e na qual o aprendiz não retém o significado dos mesmos, e por esse motivo não há uma assimilação quando novas situações são apresentadas. Nela o novo conhecimento adquire um significado para o aprendiz 
enquanto o conhecimento prévio se torna mais rico e permanente, facilitando assim o aprendizado de conteúdos mais complexos tornando possível sua aplicação nas mais diferentes áreas (MOREIRA, 2010; GOMES et al., 2008).

A comunidade acadêmica vem tomando consciência de que dominar o conteúdo ministrado em aula, não é suficiente para ensinar. É preciso aprender a ensinar. Logo, o professor precisa se adaptar a realidade de seus educandos instigando o interesse deles pelas aulas. Ao lançar um novo conteúdo, é aquele que, no início da aula, conversa com seus alunos, contextualiza o que será ensinado, dá exemplos, questiona, instiga. Então, juntamente com o aluno, constrói o texto da matéria trabalhada, observando os caminhos que essa interação traçou (RODRIGUES, MOURA e TESTA, 2011).

Na pergunta realizada acerca de julgar importante haver uma nova metodologia para ser utilizada junto à disciplina Patologia da Nutrição e Dietoterapia (Figura 2), observou-se que a maioria dos alunos que participaram da pesquisa, tanto os que se encontram no $5^{\circ}$ período ( 25 alunos), quanto os do $6^{\circ}$ período (12 alunos) responderam de forma positiva à questão levantada.

Figura 2 - Importância de haver uma nova metodologia

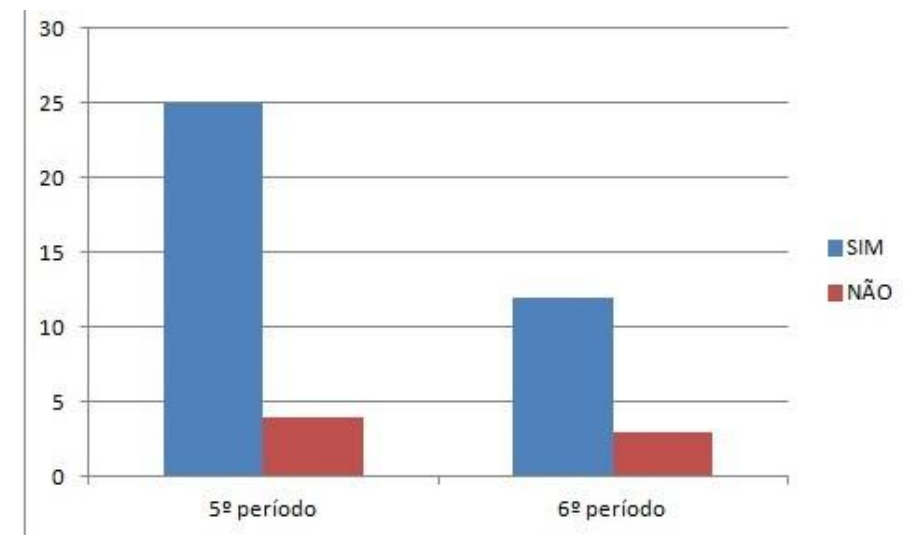

Fonte : Os autores

Esse resultado demonstra certa insatisfação dos alunos com os métodos comumente utilizados, tais como aulas expositivas, utilização de data-show e aulas teóricas muito extensas e cansativas, resultado esse que corrobora com as dificuldades apontadas anteriormente pelos alunos.

$\mathrm{Na}$ análise das justificativas os alunos do $5^{\circ}$ período (Tabela 1 ) demonstram o interesse em vivenciar o que é visto em sala de aula para um melhor entendimento, ou seja, fazer com que aquele conteúdo tenha uma significação. 
Assim como na justificativa apontada neste estudo, Scherer, Scherer e Carvalho (2006, p.289) consideram como base no processo de ensino a relação professor-aluno, aonde professores reconheçam a importância do diálogo, da troca de ideias, acreditando que é possível aprender dessa forma, e que os alunos tenham uma postura mais ativa, fazendo uma integração de informações extraídas do ambiente com as já adquiridas e interiorizadas, para que se possa fundamentar os questionamentos juntos aos professores.

Tabela 1 - Frequência das justificativas dos alunos do $5^{\circ}$ período

\begin{tabular}{l|l}
\hline Opinião & Justificativas mais apresentadas \\
\hline Sim & $\begin{array}{l}9 \text { alunos atribuíram a importância à realização de mais aulas práticas, fora } \\
\text { de sala de aula para que se possa vivenciar o conteúdo apresentado, bem } \\
\text { como a necessidade de haver uma maior interação entre o professor e o } \\
\text { aluno e a realização de mais exercícios. } \\
9 \text { alunos atribuíram a importância de uma nova metodologia para sanar } \\
\text { eventuais dificuldades que os alunos apresentem com relação ao conteúdo } \\
\text { estudado. } \\
3 \text { alunos atribuíram à importância por ser uma forma de ensino } \\
\text { complementar à sala de aula } \\
2 \text { alunos não justificaram a resposta } \\
1 \text { aluno atribuiu a importância por ser um diferencial } \\
1 \text { atribuiu a importância a ser uma forma de ajudar no aprendizado de uma } \\
\text { matéria tão extensa e diversificada. }\end{array}$ \\
\hline $\begin{array}{l}3 \text { alunos não justificaram a resposta } \\
1 \text { aluno alegou que a metodologia utilizada está boa }\end{array}$ \\
\hline Não
\end{tabular}

Fonte: Os autores

A análise das justificativas dos alunos do $6^{\circ}$ período (Tabela 2) demonstra um grande interesse dos alunos por aulas mais dinâmicas e facilitadoras da aprendizagem.

Comparando as justificativas mais frequentes dos alunos do $5^{\circ}$ e $6^{\circ}$ períodos que responderam positivamente a questão da importância de haver uma nova metodologia, observa-se que para os alunos do $5^{\circ}$ período, a realização de aulas mais práticas fora da sala de aula é tão importante quanto uma maior interação entre professor e aluno, a realização de mais exercícios, bem como minimizar eventuais dúvidas em relação ao conteúdo. Para os alunos do $6^{\circ}$ período, passar mais exemplos, realizar mais exercícios e trabalhar melhor o conteúdo se faz mais importante do que a realização de aulas mais práticas fora de sala de aula. 


\section{Ensino, Saúde e Ambiente - V9 (3), pp. 1-20, Dez. 2016}

Essa diferença nos discursos pode ser explicada pelo fato de que os alunos do $5^{\circ}$ período ainda não vivenciaram nenhum tipo de estágio curricular onde eles colocam em prática o que foi visto em sala de aula, já os alunos do $6^{\circ}$ período, nesse momento estão realizando estágio curricular na área de Alimentação Coletiva, o que de certa forma caracteriza-se por uma prática fora de sala de aula.

$\mathrm{Na}$ visão da maioria dos alunos, que participaram da pesquisa prévia (Figura 3), a realização de uma oficina seria a forma mais adequada de auxiliar no processo de ensino-aprendizagem da disciplina Patologia da Nutrição e Dietoterapia, pois de modo geral, elas constituem uma forma de se aliar a teoria com a prática.

Tabela 2 - Frequência das justificativas dos alunos do $6^{\circ}$ período

\begin{tabular}{l|l}
\hline Opinião & Justificativas mais apresentadas \\
\hline Sim & $\begin{array}{l}7 \text { alunos atribuíram a importância de uma nova metodologia à realização } \\
\text { de aulas mais dinâmicas, onde possam se passados mais exemplos, } \\
\text { praticar mais exercícios e até mesmo desenvolver algum tipo de } \\
\text { brincadeira para que o conteúdo possa ser mais facilmente assimilado. } \\
4 \text { alunos atribuíram a importância à realização de mais aulas práticas, fora } \\
\text { de sala de aula para que se possa vivenciar o conteúdo apresentado. } \\
1 \text { aluno atribuiu a importância à oposição quanto a somente o professor } \\
\text { ser o detentor do conhecimento. }\end{array}$ \\
\hline Não & $\begin{array}{l}2 \text { alunos não julgaram importante uma nova metodologia por entenderem } \\
\text { que o método praticado é o mais comum e atende às exigências da } \\
\text { disciplina. } \\
1 \text { aluno não julgou importante, pois atribuem a culpa da dificuldade de } \\
\text { aprendizagem aos alunos, por terem com uma base muito fraca. }\end{array}$ \\
\hline
\end{tabular}

\section{Fonte: Os autores}

De acordo com Paviani e Fontana (2009), conseguir conciliar a teoria que é apresentada em sala de aula com a prática é um grande desafio tanto para alunos quanto para professores. Nessa perspectiva as oficinas oferecem uma possibilidade de superar esse desafio, pois se caracterizam por proporcionar situações que articulem pressupostos teóricos com práticos. Além disso, as técnicas e os procedimentos utilizados são bastante variados, incluindo trabalhos em duplas e em grupo para promover a interação entre os participantes, sempre com foco em atividades práticas.

Kebach e Duarte (2008, p.100) acreditam que as oficinas pedagógicas constituem-se "num importante dispositivo dialético-didático para a dinamização do processo de ensino-aprendizagem" e que têm como característica a praticidade e flexibilidade, propiciando a participação efetiva dos alunos, momentos de informação, 
questionamentos, integração e aprendizagem com vistas à uma maior autonomia de alunos e professores.

Figura 1: Material de apoio apontado pelos alunos

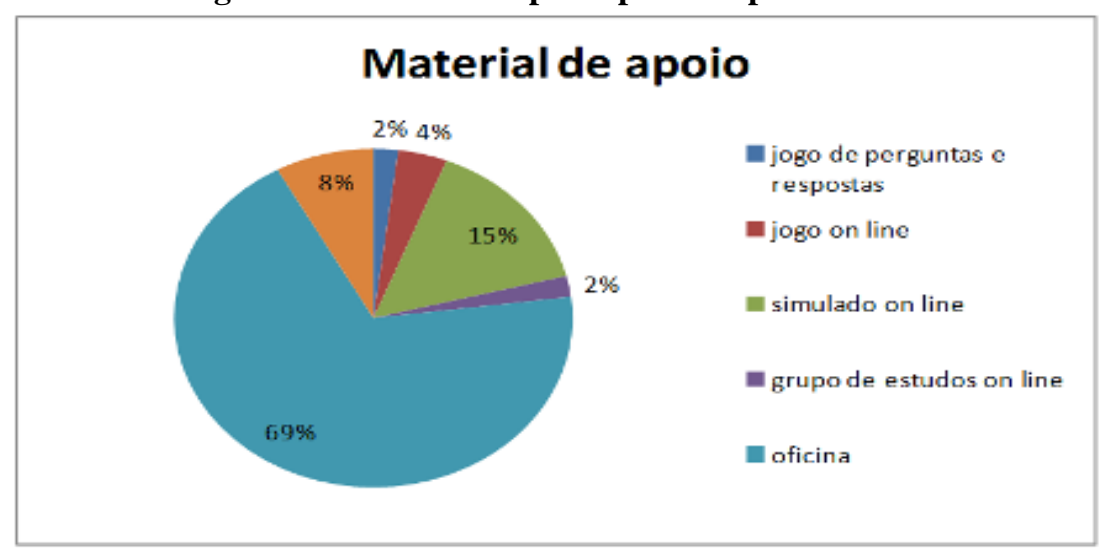

Fonte: Os autores

\section{A OFICINA PEDAGÓGICA}

O desenvolvimento da oficina ocorreu como se segue e de acordo com o roteiro elaborado e apresentado na metodologia. Inicialmente houve a apresentação da condutora da atividade. Nessa apresentação foram explicados os objetivos da oficina, o motivo do tema escolhido, os momentos e o tempo médio de duração. Não houve a necessidade de apresentação dos participantes, pois todos se conheciam.

Em um segundo momento houve uma explicação rápida sobre o tema proposto pela professora da disciplina, sobre o paciente hospitalizado. A explicação foi dividida em quatro passos que devem ser seguidos com esse paciente:

- $\quad 1^{\circ}$ passo - Consiste na avaliação nutricional desse paciente, história clínica, exame físico, inquérito de consumo alimentar em domicílio e hospitalar, avaliação bioquímica e antropometria;

- $\quad 2^{\mathrm{o}}$ passo - Estimativa das necessidades nutricionais do paciente;

- $\quad 3^{\circ}$ passo - Recomendação do tratamento nutricional de acordo com as necessidades do paciente;

- $\quad 4^{\circ}$ passo - A forma de alimentação desse paciente, ou seja, que tipo de dieta hospitalar será recomendada para ele.

Logo após, iniciou-se o resgate dos conhecimentos dos alunos acerca do tema para que pudéssemos ter uma ideia de como se encontrava o nível deste conhecimento. Perguntas acerca do que eles sabiam sobre cada passo descrito acima. As palavras- 


\section{Ensino, Saúde e Ambiente - V9 (3), pp. 1-20, Dez. 2016}

chave das falas dos alunos foram escritas no quadro para que fossem utilizadas posteriormente durante as discussões.

Houve a apresentação de uma situação problema por parte da condutora, a partir dos conhecimentos prévios dos alunos, elencados no quadro. A situação consistiu em um caso clínico fictício. Os alunos participantes puderam discutir entre eles e pesquisar no material que dispunham sobre a temática, que era o disponibilizado pela professora em sala durante as aulas.

Por fim os alunos apresentaram a conduta que teriam diante do problema exposto e fizemos a simulação de um preenchimento de um prontuário.

Como o grupo participante foi pequeno, não houve uma discussão após a apresentação da conduta, visto que já tinham feito isso entre eles anteriormente.

A avaliação que se seguiu não foi verbal e sim por meio de um questionário, pois ela seria parte dos resultados deste trabalho.

A análise das respostas dos alunos, que participaram da oficina, acerca da proposta metodológica utilizada demonstra que os mesmos ficaram satisfeitos e avaliaram positivamente a utilização da oficina como ferramenta de apoio ao ensino da disciplina Patologia da Nutrição e Dietoterapia.

Como objetivos da oficina, destacam-se os seguintes: auxiliar os estudantes no aperfeiçoamento de suas estratégias de estudo e no controle do tempo para as atividades acadêmicas; abrir espaço para discussão das dificuldades de rendimento acadêmico e sua relação com a motivação e satisfação com o curso (BASSO et al., 2013).

Todos os alunos que participaram da oficina $(n=5)$ declararam que a mesma atendeu as suas expectativas; acharam suficiente o tempo de realização da oficina, bem como classificaram como bons os materiais disponibilizados e os recursos utilizados. Dos cinco participantes da oficina, somente um não soube opinar sobre o uso da metodologia da problematização, os demais avaliaram positivamente.

Isso se deve ao fato de que:

Nas oficinas o aluno executa tarefas com responsabilidade, tornando-se participante ativo no processo de aprendizagem. Professor e aluno estão envolvidos no trabalho como colaboradores, buscando a resolução das tarefas estabelecidas no projeto em execução. É o que se pode chamar de liberdade com responsabilidade, tudo isso aliado ao prazer de ver o resultado final (HEINEN, 2003, p. 11).

Oliveira et al. (2014) relataram que, em seu estudo realizado com estudantes universitários de uma universidade púbica do Rio Grande do Sul, as oficinas realizadas atenderam de forma plena as expectativas dos participantes, bem como atividades 


\section{Ensino, Saúde e Ambiente - V9 (3), pp. 1-20, Dez. 2016}

propostas, recursos utilizados e indicação de leituras foram avaliados de forma positiva e considerados como facilitadores da aprendizagem.

As oficinas são um incentivo ao desafio, ao questionamento e à reflexão, buscando respostas alternativas aos problemas detectados, e não apenas imitando soluções já existentes (HEINEN, 2003)

Quando questionados sobre o auxílio que o conteúdo abordado prestou ao aprendizado da disciplina Patologia da Nutrição e Dietoterapia, todos os alunos responderam positivamente à questão. Dessa forma acreditamos que a organização e elaboração do conteúdo a ser trabalhado em uma oficina deve ser bem pesquisado para que todas as informações contidas sejam atuais e confiáveis.

Colman (2003, p.15) destaca que:

Os participantes esperam, certamente, que o moderador conheça profundamente os assuntos que estão sendo apresentados. As pessoas gostam de ouvir relatos de acontecimentos e experiências, da vivência do educador no tema ou assunto; isso torna o momento de aprendizagem mais interessante.

Nas oficinas, o trabalho em grupo destaca-se como um meio integrador e interdisciplinar, fazendo em que haja espaço para a criatividade, curiosidade e capacidade de observação dos participantes (HEINEN, 2003).

Basso et al. (2013, p.283), em estudo realizado com alunos de graduação da Universidade Federal de Santa Catarina, destacou que os mesmos avaliaram dentre os aspectos positivos da realização de uma oficina a promoção de autoconhecimento, as técnicas utilizadas, atividades feitas em grupo, forma e apresentação do conteúdo, aproximação entre teoria e prática, ambiente acolhedor e compartilhamento de experiências.

Por fim, na resposta ao questionamento sobre em que a oficina contribuiu no seu desempenho acadêmico e/ou no seu futuro profissional, os alunos demonstraram satisfação, um melhor entendimento do conteúdo da matéria, e que a oficina auxiliou nos obstáculos encontrados por eles a respeito da disciplina, como se verá nas falas a seguir:

"Sim. Me auxiliou no esclarecimento da matéria." (P1)

"A oficina instruiu e auxiliou bastante nos obstáculos encontrados na disciplina." (P2)

"A oficina auxiliou a complementar o conteúdo abordado na matéria do período, visualizando melhor um paciente hospitalizado." (P3)

"Abriu meu entendimento sobre a matéria." (P4)

"Passei a entender melhor os conteúdos, tendo uma melhor fixação dos assuntos abordados." (P5) 
A opinião dos alunos é muito importante, pois alia a expectativa com a necessidade de transferência de informação. A problematização é a busca do fato concreto - como fazer, como utilizar - resultante do conhecimento adquirido (FONTOURA, 2011).

Práticas que facilitem a integração entre conhecimentos teóricos e conhecimentos baseados na experiência são valiosas para o desempenho dos profissionais de saúde, visto que tomar decisões que influenciam a vida de outras pessoas, faz parte da rotina desses profissionais (FAGUNDES e BURNHAM, 2005).

Mendes et al. (2012, p.237) ressaltam que:

$\mathrm{Na}$ formação superior em geral, tem-se assistido uma implementação gradual de novos modelos educacionais estimulantes e participativos, no sentido de remeter o estudante a buscar soluções para problemas vivenciais, relacionando teoria e prática.

Almeja-se que as universidades poderiam ampliar os espaços para que esse tipo de conhecimento seja construído por meio da manutenção de oportunidades e criação de ações inovadoras, como é o exemplo das oficinas (OLIVEIRA et al., 2014).

\section{CONCLUSÕES}

De acordo com os resultados da pesquisa, conclui-se que a importância de se integrar a teoria e a prática dentro do contexto de sala de aula se dá pelo fato de que os alunos tendem a se sentir inseguros ao colocarem em prática seus conhecimentos teóricos, adquiridos ao longo do curso, bem como, estão propondo uma ruptura ao modelo tradicional de ensino, visto que aulas de caráter puramente teórico não trazem significação e, consequentemente, não propiciam a aprendizagem de forma a preparar esse aluno a enfrentar os desafios no mercado de trabalho.

Estão preocupados com seu desempenho em sala de aula, pois a grande maioria reconhece a importância de uma nova metodologia à realização de aulas mais dinâmicas, menos formal em busca de uma melhor fixação do conteúdo a ser assimilado, onde possam ser passados mais exemplos, praticando-se mais exercícios e havendo uma maior interação entre professor e aluno.

Concluiu-se também que a escolha da realização de uma oficina para ajudar no aprendizado se deu pelo fato de que elas constituem um ambiente de interação, onde todos ensinam e aprendem. 
A oficina atendeu as expectativas dos alunos, pois houve participação dos mesmos esclarecendo dúvidas, relatando experiências vivenciadas e realizando um trabalho em conjunto.

Ainda foi possível concluir que o tempo utilizado nas oficinas, o conteúdo abordado, os materiais utilizados, bem como o uso da metodologia da problematização foram considerados adequados e avaliados de forma positiva.

Portanto, os alunos participantes da pesquisa, de um modo geral e em sua grande maioria, almejam aulas que se diferenciem do modelo tradicional e buscam novas formas de aprendizado.

Cabe aos docentes, acompanhar as mudanças na dinâmica das novas gerações e sua relação com a informação e o conhecimento, para que ao fim, as aulas sejam efetivamente produtivas e cumpram o seu objetivo maior, que é o de ensinar.

\section{REFERÊNCIAS BIBLIOGRÁFICAS}

BASSO, C. et al. Organização de tempo e métodos de estudo: Oficinas com estudantes universitários. Revista Brasileira de Orientação Profissional, v.14, n.2, p. 277-288, 2013.

BERBEL, N.A.N. As metodologias ativas e a promoção da autonomia de estudantes. Semina: Ciências Sociais e Humanas, v.32, n.1, p.25-40, 2011.

BRASIL. Resolução CNE/CES nº5, de 7 de Novembro de 2001. Institui Diretrizes Curriculares Nacionais do Curso de Graduação em Nutrição. Disponível em: $<$ http://portal.mec.gov.br/cne/arquivos/pdf/CES05.pdf> Acesso em Agosto de 2013.

COLMAN, F.T. Tudo que o enfermeiro precisa saber sobre treinamento: um manual prático. Rio de Janeiro: Guanabara Koogan, 2003.

DEBALD, B.S. A docência no ensino superior numa perspectiva construtivista. In: Estado e Políticas Sociais no Brasil, Seminário Nacional. Cascavel, PR , 2003, p.2.

DELORS, J. Educação: Um Tesouro a Descobrir. Relatório para a UNESCO da Comissão Internacional sobre Educação para o Século XXI. Brasília, DF: UNESCO, 2010. Disponível em: http://unesdoc.unesco.org/images/0010/001095/109590por.pdf Acesso em 28 de out. 2015.

FAGUNDES, N.C.; BURNHAM, T.F. Discutindo a relação entre espaço e aprendizagem na formação de profissionais de saúde. Interface - Comunicação, Saúde, Educação, v.9, n.16, p.105-114, 2005.

FONTOURA, H.A. Tematização como proposta de análise da dados na pesquisa qualitativa. In: FONTOURA, H. A (Org.) Formação de professores e diversidades culturais: múltiplos olhares em pesquisa. Niterói: Intertexto, 2011. 
FRANCO, A.C.; BOOG, M.C.F. Relação teoria-prática no ensino de educação nutricional. Revista de Nutrição, v.20, n.6, p.643-655, 2007.

FREIRE, P. Pedagogia do Oprimido. 17ª 19L. Rio de Janeiro: Paz e Terra, 1987. HEINEN, L.M.B. Vivenciando a realidade do ensino da língua materna: uma experiência realizada por acadêmicos em União da Vitória. 2003. 96f. Dissertação (mestrado). Centro de Ciências Humanas, Letras e Artes. Universidade Estadual de Maringá. Maringá. 2003.

KEBACH, P.F.C.; DUARTE, R. Oficinas Pedagógicas Musicais: Espaço Construtivista Privilegiado de Formação Continuada. Revista Eletrônica de Psicologia e

Epistemologias Genéticas, v.1, n.2, p.95-112, 2008.

MENDES, G et al. Contributos da aprendizagem baseada em problemas no desempenho do estudante de enfermagem em ensino clínico. Revista de Formación e Innovación Educativa Universitaria, v.5, n.4, p.227-240, 2012.

MOITA, F.M.G.S.C.; ANDRADE, F.C.B. O saber de mão em mão: a oficina pedagógica como dispositivo para a formação docente e a construção do conhecimento na escola pública. REUNIÃO ANUAL DA AMPED, v.29, p.16, 2006

MOREIRA, M.A. Linguagem e Aprendizagem Significativa. Encontro Internacional sobre Aprendizagem Significativa, 2003. Disponível em:

<http://www.if.ufrgs.br/ moreira/linguagem.pdf > Acesso em: Novembro de 2015.

Aprendizagem Significativa Crítica. $2^{\text {a }}$ edição, 2010. Disponível em: <

http://www.marcoantoniomoreira.com.br/homepage.html> Acesso em: Agosto de 2013.

MOTTA, D.G.; OLIVEIRA, M.R.M.; BOOG, M.C.F. A formação Universitária em Nutrição. Pro-Posições, v.14, n.1, 2003.

OLIVEIRA, C.T. et al. Oficinas de Elaboração de Comunicação e Escrita Científica com Estudantes Universitários. Revista Psicologia: Ciência e Profissão, V.34, n.1, p.252-263, 2014.

PAVIANI, N.M.S.; FONTANA, N.M. Oficinas Pedagógicas: relato de uma experiência. Conjectura: filosofia e educação, v.14, n.2, p.77-88, 2009.

PEDROSO, M.B.; CUNHA, M.I. Vivendo a inovação: as experiências no curso de nutrição. Interface - Comunic., Saúde, Educ., v.12, n.24, p.141-152, 2008.

PONTES, A.L.; REGO, S.; JÚNIOR, A.G.S. Saber e Prática Docente na Transformação do Ensino Médico. Revista Brasileira de Educação Médica, v.30, n.2, p.66-75, 2006.

PORTELA, A.L.; LUKE, H.; SILVA, A.F.G. Oficina Pedagógica 8: Gestão Pedagógica da Educação Escolar. In: PRADIME: programa de apoio aos dirigentes municipais de Educação/ Ministério da Educação. Secretaria de Educação Básica. Caderno de oficinas - Volume 3. Brasília, DF: Ministério da Educação, 2006. 
RODRIGUES, L.P.; MOURA, L.S.; TESTA, E. O tradicional e o moderno quanto à didática no ensino superior. Revista Científica do ITPAC, v.4, n.3, 2011.

SCHERER, Z.A.P.; SCHERER, E.A.; CARVALHO, A.M.P. Reflexões sobre o ensino da enfermagem e os primeiros contatos do aluno com a profissão. Revista LatinoAmericana de Enfermagem, v.14, n.2, p.285-291, 2006.

SOUZA, N.A. A relação teoria-prática na formação do educador. Semina: Ciências Sociais e Humanas, v.22, p.5-12, 2001.

UNIFOA - Centro Universitário de Volta Redonda (Volta Redonda, RJ). Projeto pedagógico curso de Nutrição. Volta Redonda, 2013. 168 p.

VASCONCELOS, F.A.G. ; CALADO, C.L.A. Profissão Nutricionista: 70 anos de história no Brasil. Revista de Nutrição, v.24, n.4, p.605-617, 2011.

VEIGA, I.P.A. Nos laboratórios e oficinas escolares: a demonstração didática. In: FELTRAN FILHO, A. et al. Técnicas de ensino: Por que não? Campinas, SP: Papirus, 1991. 